\title{
Tear-drop technique in iliac screw placement: a technical analysis
}

\author{
Stephan Nowak ${ }^{1}$ (D) Jonas Müller ${ }^{1} \cdot$ Martin E. Weidemeier $^{1} \cdot$ Henry W. S. Schroeder $^{1} \cdot$ Jan-Uwe Müller $^{1}$
}

Received: 2 November 2020 / Accepted: 22 February 2021 / Published online: 5 March 2021

(C) The Author(s) 2021

\begin{abstract}
Background Instrumentation of the lumbosacral region is one of the more challenging regions due to the complex anatomical structures and biomechanical forces. Screw insertion can be done both navigated and based on X-ray verification. In this study, we demonstrate a fast and reliable open, low exposure X-ray-guided technique of iliac screw placement.

Methods Between October 2016 and August 2019, 48 patients underwent sacropelvic fixation in tear-drop technique. Screw insertion was performed in open technique by using an X-ray converter angulated $25-30^{\circ}$ in coronal and sagittal view. The anatomical insertion point was the posterior superior iliac spine. Verification of correct screw placement was done by intraoperative 3D scan.

Results In total, 95 iliac screws were placed in tear-drop technique with a correct placement in $98.1 \%$.

Conclusions The tear-drop technique showed a proper screw position in the intraoperative 3D scan and therefore may be considered an alternative technique to the navigated screw placement.
\end{abstract}

Keywords Iliac screw $\cdot$ Tear-drop $\cdot$ Spine $\cdot$ Surgical technique $\cdot$ Surgery $\cdot$ X-ray $\cdot$ Screw placement $\cdot$ Spinal surgery

\section{Introduction}

Instrumentation of the lumbosacral region is one of the more challenging regions due to the complex anatomical structures and biomechanical forces [5, 14]. Especially multilevel fusions including the sacral area for adult deformity, lumbosacral instability, or stenosis are associated with poor clinical outcome. Often, the rates of major complications, pseudarthrosis (up to 33\%), and implant failure are high [4]. To reduce the rate of the aforementioned complications, multiple techniques to support the S1 pedicle screws were developed. It has been demonstrated that additional iliac fixation enhances the fusion rate of the lumbosacral junction $[9,11]$. Numerous techniques have been developed for iliac fixation [15]. Especially S2 ala-iliac and iliac screws, both techniques lead to biomechanical good results $[1,12]$. Due to no prominence of the screwhead in thin patients and the possibility to directly connect to the fixation system without offset

This article is part of the Topical Collection on Spine degenerative

Stephan Nowak

stephan.nowak@med.uni-greifswald.de

1 Universitätsmedizin Greifswald, Klinik und Poliklinik für Neurochirurgie, Sauerbruchstraße, 17475 Greifswald, Germany connectors, the $\mathrm{S} 2$ ala-iliac screws are preferred. Next to open surgical techniques for iliac fixation with anatomic guidance, also navigated or robotic-supported placements have been described $[8,14]$. Already good to excellent accuracy can be achieved with these technically assisted methods. Under robotic guidance, an accuracy rate of $95.7 \%$ can already be achieved [10]. Only free-hand technique followed by navigated screw placement can achieve better accuracy with $100 \%$ vs. 98\% respectively [8]. These techniques, if applied correctly, have the advantage to give the surgeon an extra reference for safety at the cost of prolonged operative time and radiation exposure relative to conventional fluoroscopy-based methods $[2,7,13]$. That is why we adapted a fast and simple radiological controlled open placement technique for iliac screw fixation at our neurosurgical spine center.

\section{Materials and methods}

Between October 2016 and August 2019, 48 patients underwent sacropelvic fixation in tear-drop technique. Between 2016 and 2019, all patients who received iliac screw placement were included. Only in one case, iliac screw placement was achieved in navigated technique (due to neoplastic sacrum deformity). This case was excluded. To indicate surgery, we applied generally accepted standards in every 
specific case. The preoperative diagnostic procedure included a thorough anamnesis and clinical examination. The preoperative imaging included an MRI and CT of the lumbar spine. Intraoperative screw position was verified with a 3D X-ray scan with c-arm. Follow-up X-ray was performed before discharge and 3 months after surgery. The data was collected prospectively. The chart review was done retrospectively. The statistical analysis was done by using Excel and SPSS for Windows.

\section{Surgical technique}

All surgical procedures were performed by our senior spine surgeon and senior author (J.-U. Müller). Our spinal instrumentation system and pedicle screws used in all cases of this study are from Signus Medizintechnik (Signus GmbH, Alzenau, Germany).

Surgery is performed in general anesthesia with the patient being in prone position. Spinal exposure is obtained via a standard midline incision from the lumbar spine to the sacrum. The distal extent of the incision should be lower than the line between the posterior superior iliac spine (PSIS). The traditional anatomical landmark for iliac screw fixation is the PSIS [9]. The bony PSIS will be exposed bluntly. The X-ray converter will be angled $25-30^{\circ}$ in coronal and sagittal plane with a prone position of the patient, unlike the iliac oblique view where the patient is rotated $45^{\circ}$ by wedge elevation, leading to a completely different pelvic image. Figure 1 shows the correct intraoperative X-ray alignment. To confirm proper X-ray view, a "tear-drop sign," as depicted in Fig. 2, must be visible. The outer edges of the "tear-drop sign" will be formed by the cortical layers of the iliac bone. The tear-drop sign will lead
Fig. 1 Correct X-ray alignment in $25^{\circ}$ sagittal and coronal plane with inserted awl

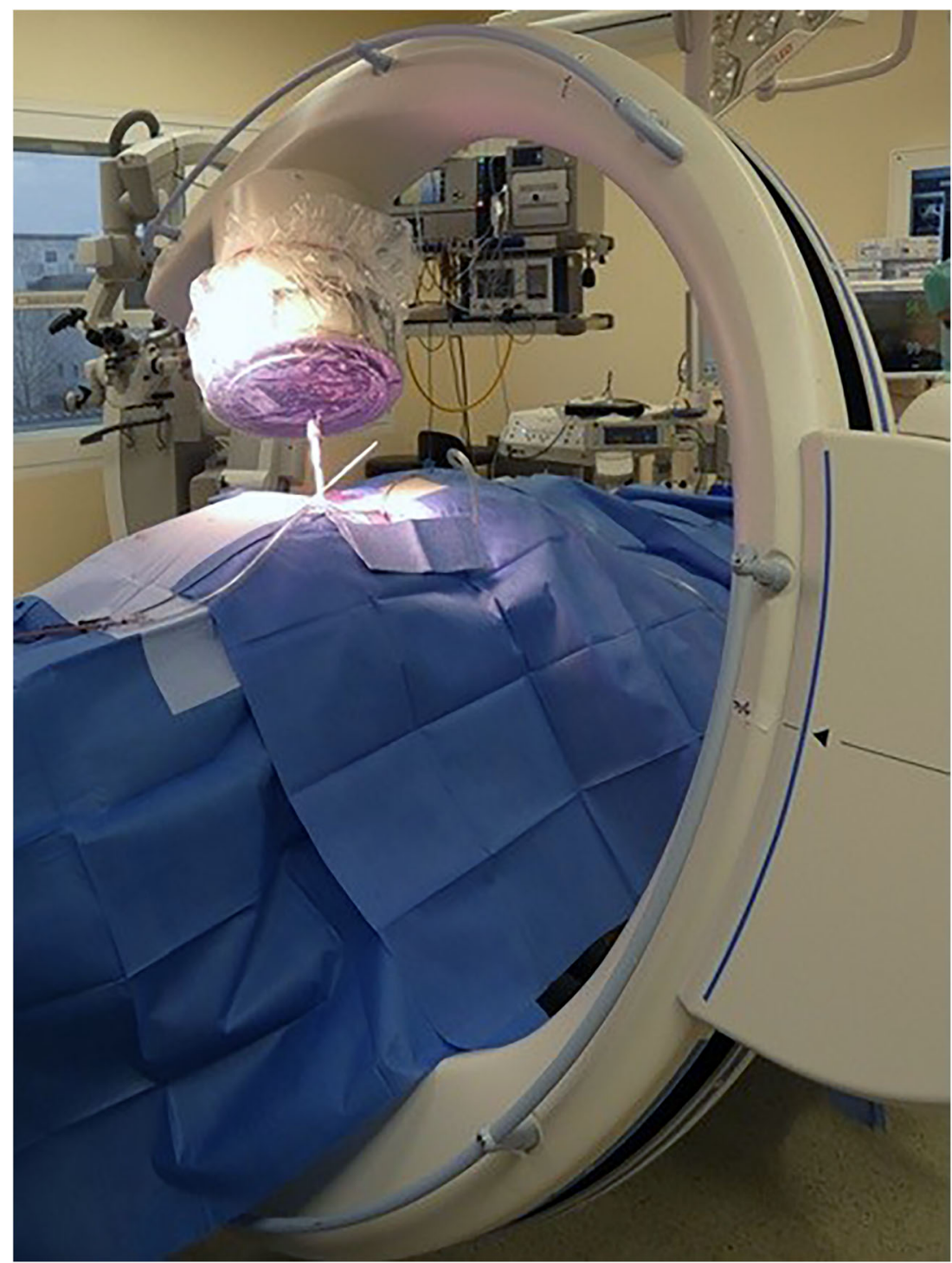


the direction of the screw insertion. The screw has to be placed directly in the middle of the tear-drop sign. Ideally there is a direct look on view of the screw inside the tear-drop as depicted in Fig. 3. The burr channel will be prepared medial to the PSIS via a bone awl followed by a proper check using a probe. Then, a guide wire will be inserted under guidance of the tear-drop sign. The medial PSIS will be opened with a chisel for the screw head which should later sink into the burr hole. This step is important as otherwise the screw head can be prominent under the skin, even more so in skinny patients. Commonly an $8.5 \times 80 \mathrm{~mm}$ screw will be inserted. We use preoperative imaging and intraoperative probe to determine the best suitable screw length and diameter. The screw should not breach through the tear-drop sign in the X-ray overview. After screw placement, a 3D X-ray will be performed to rule out sciatic notch or acetabular breach. The iliac screws will be connected to the screw rod via an offset connector. We are convinced that a direct connection with the lumbosacral fixation system would bring too much force on the distal rod thus leading frequently to rod fracture and pseudarthrosis. In the postoperative period, the patient will be hospitalized for 1 week. Before discharge, a common X-ray will be performed.

\section{Results}

Between October 2016 and August 2019, we included 48 patients. A total of 27 of them were female and 21 male. The mean age was 64 years (27-81 years). In all cases, bilateral iliac screw positioning was performed. In total, 95 iliac screws were placed in tear-drop technique. Only in one side $(1.04 \%)$, navigated placement was performed due to tumor which deformed the iliac anatomy. The mean follow-up was
9.8 months, ranging from 7 days to 27 months. Spinal instrumentation was performed due to degenerative spinal scoliosis in 22 cases (45.8\%). In an equal number ( 22 cases; $45.8 \%$ ), a revision surgery after previous spinal instrumentation needed spinopelvic fusion. Of that group, there were 7 cases with pseudarthrosis of L5/S1 (14.6\% from the whole cohort). All cases received a multilevel spinal instrumentation. Pseudarthrosis of the sacroiliac joint after multilevel spinal instrumentation was seen in 3 cases $(6.2 \%$ of the whole cohort). Spinal trauma involving the sacrum and pelvic tumor infiltration contributed 2 cases each (4.2\%). On average, $8 \mathrm{X}$ ray images were needed to adjust the tear-drop sign, make the pre-drilling, and place the screw on one side. The radiation exposure depends on the X-ray converter used and the technical settings applied by the surgeon. On average, our X-ray converter takes $83 \mathrm{kV}$ and $9.1 \mathrm{~mA}$. In all cases but one, the 3D $\mathrm{X}$-ray scan after tear-drop screw placement confirmed a correct position of the screw (98.9\%). In one case, there was a lateral breach of the screw head. Prior to the 3D X-ray scan, no redirection of a screw was needed. In the 3-month follow-up, there were no complications regarding the iliac screws. In the overall follow-up time, there were no complications involving the iliac screw, up until today. Other surgical complications included postoperative infection in 4 cases $(8.3 \%)$, non-fusion of the upper and mid-level in 4 cases $(8.3 \%)$, and fractured pedicle screw on level L2 in one case $(2.1 \%)$.

\section{Discussion}

The addition of iliac fixation should be considered in multilevel spinal fusion including the lumbosacral crossover in adult deformity and instability to reduce the risk of
Fig. 2 Cortical layers of the iliac bone from the "tear-drop sign" (blue arrow)

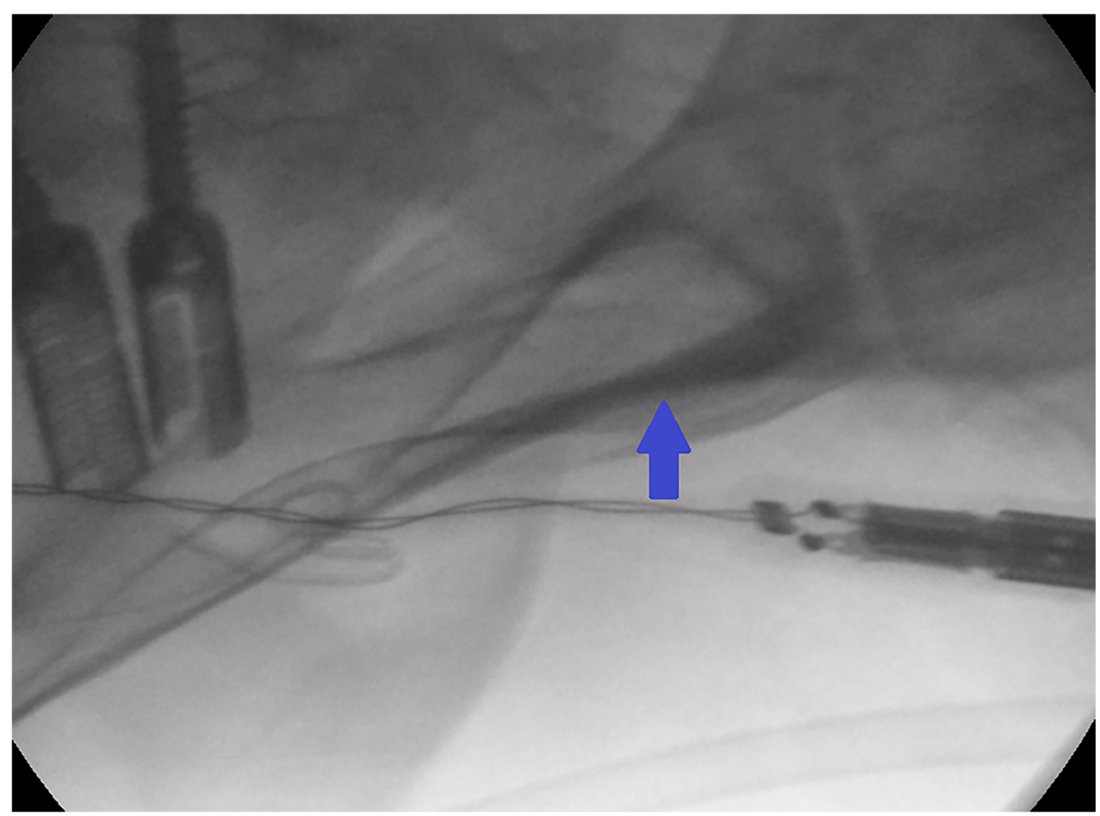




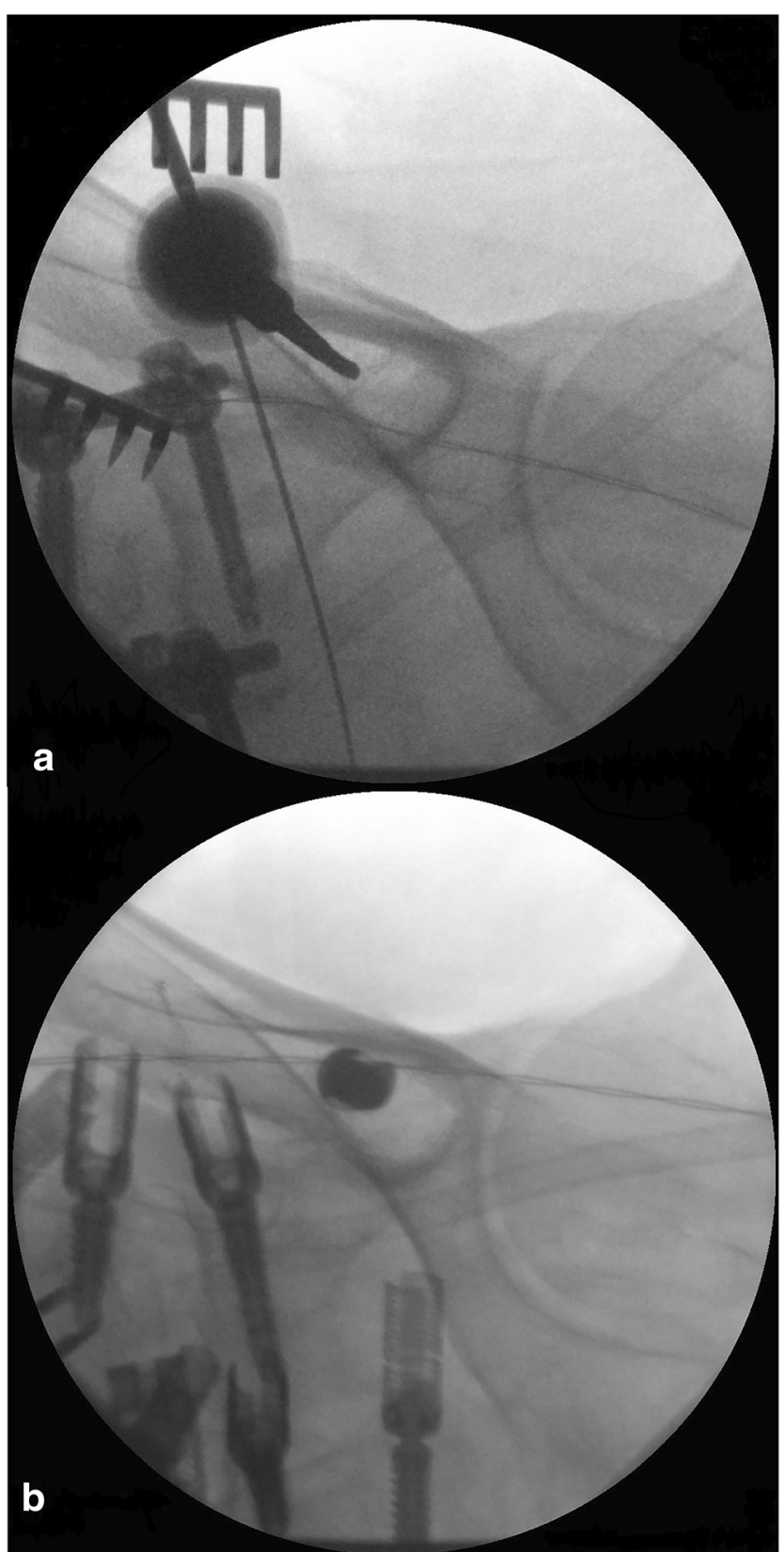

Fig. 3 Correct placement of the iliac screw in "tear-drop" technique without wall breach. a Correct insertion of the awl inside the tear-drop sign. b Correct placement of the iliac screw

lumbosacral pseudarthrosis $[9,11]$. In our institution, we use the tear-drop technique for iliac screw placement in every case of normal pelvic anatomy. We only switch to navigated screw placement in case of trauma with changed pelvic anatomy, congenital spinal and pelvic derangement, or instability due to tumor infiltration with pelvic involvement.

The radiographically guided tear-drop technique combines the advantages of both free-hand and navigated placement techniques. The exposure level is minimal, as we use the existing surgical corridor for spinopelvic fusion. Only a minimal exposure of the PSIS will be performed for visualization and preparation of the entry point. Additionally, the radiological exposure level will be low. The tear-drop sign must be adjusted on the X-ray monitor and the screw placed under radiological guidance. We recommend, if available, a 3D scan directly after screw placement in open as well as in navigated placement to ensure a correct screw position without breach.

The technique necessitates at least a c-arm X-ray apparatus and a carbon surgical table to ensure visualization. Also, it is important to align the tear-drop sign in the central X-ray beam as otherwise a visual aberration can lead to wrong screw position leading to screw breach. A recent meta-analysis comparing iliac screw placement with S2 ala-iliac screw placement detected mechanical complications in up to $27.9 \%$ of the cases vs. $14.2 \%$ respectively [3]. Our rate of wound infections is $8.6 \%$ and for being related to a complex spinal procedure, we consider this an acceptable range [16]. It is important to note though that the overall infection rate depends strongly on other factors of the performed procedure (i.e., total number of screws being placed, level of fusion, trauma) and is therefore not a viable indicator for pure iliac screw safety.

When comparing to other free-hand techniques, as for example proposed by Fridley et al., we achieve comparable results [6]. In their technique, no X-ray guidance is used. However, we would like to note that a radiological reference often will be needed due to anatomical variations, listhesis, trauma, or tumor.

\section{Conclusion}

The tear-drop technique for iliac screw placement in spinal surgery is a reliable and safe method only utilizing standard $\mathrm{X}$-ray imaging and minimal exposure of the surgical field.

Funding Open Access funding enabled and organized by Projekt DEAL.

\section{Declarations}

Ethical approval All procedures performed in studies involving human participants were in accordance with the ethical standards of the institutional and/or national research committee (Ethikkommission an der Universitätsmedizin Greifswald) and with the 1964 Helsinki declaration and its later amendments or comparable ethical standards.

Informed consent For this type of study, formal consent is not required.

Conflict of interest The authors declare no competing interests.

Open Access This article is licensed under a Creative Commons Attribution 4.0 International License, which permits use, sharing, adaptation, distribution and reproduction in any medium or format, as long as you give appropriate credit to the original author(s) and the source, provide a link to the Creative Commons licence, and indicate if changes were made. The images or other third party material in this article are included in the article's Creative Commons licence, unless indicated otherwise in a credit line to the material. If material is not included in the article's 
Creative Commons licence and your intended use is not permitted by statutory regulation or exceeds the permitted use, you will need to obtain permission directly from the copyright holder. To view a copy of this licence, visit http://creativecommons.org/licenses/by/4.0/.

\section{References}

1. Burns CB, Dua K, Trasolini NA, Komatsu DE, Barsi JM (2016) Biomechanical comparison of spinopelvic fixation constructs: iliac screw versus S2-alar-iliac screw. Spine Deform 4(1):10-15

2. Choo AD, Regev G, Garfin SR, Kim CW (2008) Surgeons' perceptions of spinal navigation: analysis of key factors affecting the lack of adoption of spinal navigation technology. SAS J. 2(4):189194

3. De la Garza Ramos R, Nakhla J, Sciubba DM, Yassari R (2019) Iliac screw versus S2 alar-iliac screw fixation in adults: a metaanalysis. J Neurosurg Spine. 30(2):253-258

4. Edwards CC, Bridwell KH, Patel A, Rinella AS, Berra A, Lenke LG (2004) Long adult deformity fusions to L5 and the sacrum. A matched cohort analysis. Spine (Phil Pa) 15(18):29

5. Emami A, Deviren V, Berven S, Smith JA, Hu SS, Bradford DS (2002) Outcome and complications of long fusions to the sacrum in adult spine deformity: Luque-Galveston, combined iliac and sacral screws, and sacral fixation. Spine 27:776-786

6. Fridley J, Fahim D, Navarro J, Wolinsky JP, Omeis I (2014, 2014) Free-hand placement of iliac screws for spinopelvic fixation based on anatomical landmarks: technical note. Int J Spine Surg. https:// doi.org/10.14444/1003

7. Harrop JS, Jeyamohan SB, Sharan A, Ratliff J, Vaccaro AR (2009) Iliac bolt fixation: an anatomic approach. J Spinal Disord Tech 22: $541-544$
8. Hlubek RJ, Almefty KK, Xu DS, Turner JD, Kakarla UK (2017) Safety and accuracy of freehand versus navigated iliac screws: results from 222 screw placements. Spine (Phila Pa 1976) 42(20): E1190-E1196

9. Kebaish KM (2010) Sacropelvic fixation: techniques and complications. Spine (Phila Pa 1976) 35:2245-2251

10. Laratta JL, Shillingford JN, Lombardi JM, Alrabaa RG, Benkli B et al (2018) Accuracy of S2 alar-iliac screw placement under robotic guidance. Spine Deform. 6(2):130-136

11. Lattig F, Weckbach S (2017) S2-Ala-iliac screws for extended pelvic fixation in longer lumbar instrumentation. Oper Orthop Traumatol 29:360-372

12. O'Brian JR, Yu WD, Kaufman BE, Bucklen B et al (2013) Biomechanical evaluation of S2 alar-iliac screws: effect of length and quad-cortical purchase as compared with iliac fixation. Spine 38:E1250-E1255

13. Pennington Z, Cottrill E, Westbroek EM, Goodwin ML, Lubelski D, Ahmed AK, Sciubba DM (2019) Evaluation of surgeon and patient radiation exposure by imaging technology in patients undergoing thoracolumbar fusion: systematic review of the literature. Spine J Aug 19(8):1397-1411

14. Seung-Jae H, Ki-Jeong K, Tae-Ahn J (2017) S2 alar iliac screw placement under robotic guidance for adult spinal deformity patients: technical note. Eur Spine J 26:2198-2203

15. Sohn S, Chung CK, Kim YJ, Kim CH, Park SB, Kim H (2016) Modified iliac screw fixation: technique and clinical application. Acta Neurochir (Wien) 158(5):975-980

16. Zhou J, Wang R, Huo X, Xiong W, Kang L, Xue Y (2020) Incidence of surgical site infection after spine surgery: a systemic review and meta-analysis

Publisher's note Springer Nature remains neutral with regard to jurisdictional claims in published maps and institutional affiliations. 